\title{
Gambaran Stres Kerja pada Karyawan di Proyek PLTGU Muara Tawar PT Hutama Karya Kabupaten Bekasi
}

\author{
Annisa Tria Widiaty, Rizki Amalia, Dyah Utari, Nayla Kamilia Fithri \\ Program Studi Kesehatan Masyarakat, Fakultas Ilmu Kesehatan \\ Universitas Pembangunan Nasional Veteran Jakarta
}

\begin{abstract}
Abstrak
Latar belakang: Tempat kerja merupakan salah satu tempat dimana pemicu stres dapat berkembang. Stres kerja merupakan hal umum yang dapat dialami oleh para pekerja. Stres kerja dapat diakibatkan karena ketidakmampuan pekerja dalam memenuhi tuntutan untuk menyelesaikan pekerjaannya atau adanya rasa ketidaknyamanan dan ketidakpuasan dalam bekerja. Beban kerja yang banyak, tenggang waktu yang sedikit, komunikasi antar pekerja yang kurang baik, serta faktor lainnya dapat menjadi sumber stres. Tujuan penelitian ini untuk mengetahui gambaran stres kerja pada karyawan di Proyek PLTGU Muara Tawar PT Hutama Karya.

Metode: Jenis penelitian ini yaitu deskriptif kuantitatif dengan desain cross-sectional. Populasi penelitian ini yaitu seluruh karyawan di Proyek PLTGU Muara Tawar PT Hutama Karya. Sampel yang digunakan sejumlah 118 karyawan. Teknik pengambilan sampel dengan simple random sampling. Analisis data menggunakan analisis univariat.

Hasil: Hasil penelitian menunjukkan sebanyak 24 karyawan (20,3\%) tidak mengalami stres kerja, 89 karyawan $(75,4 \%)$ mengalami stress kerja ringan, dan 5 karyawan (4,2\%) mengalami stres kerja sedang.

Kesimpulan: Sebagian besar karyawan di Proyek PLTGU Muara Tawar PT Hutama Karya mengalami stres kerja ringan. Oleh karena itu, pekerja disarankan untuk menerapkan manajemen stres agar dapat mencegah stres sedini mungkin, memanfaatkan waktu istirahat dalam bekerja sebaik mungkin, dan melakukan interaksi sosial antar pekerja untuk terciptanya hubungan dalam pekerjaan yang baik.
\end{abstract}

Kata kunci : Stres Pekerjaan, Pekerja, Pembangkit Listrik

\section{Occupational Stress Level Among Employees at PLTGU Muara Tawar Project PT Hutama Karya Bekasi}

\begin{abstract}
Background: Workplace is one of the places where stressors can be develop. Occupational stress is a common thing that can be experienced by the employees. Occupational stress can be caused by or due to, please choose one the inability of the employees to meet the demands to complete their work or the feeling of discomfort and dissatisfaction at work. Lots of workloads, short period of time, poor communication between employees, and other factors can be the source of occupational stress. The purpose of this study was to determine the description of occupational stress among employees at PLTGU Muara Tawar Project PT Hutama Karya.

Methods: This study was a descriptive quantitative research with cross-sectional design. The population of this research is all employees at the Muara Tawar PLTGU Project PT Hutama Karya. The sample was 118 employees. The sampling technique used was simple random sampling. Data were analyzed in proportion and frequency.

Result: The results showed that 24 employees (20,3\%) were never had occupational stress, 89 employees (75,4\%) had mild occupational stress, and 5 employees (4,2\%) had moderate occupational stress.

Conclusion: Most of the employees at PLTGU Muara Tawar Project PT Hutama Karya had mild occupational stress. Therefore, employees are recommended to apply stress management in order to prevent stress, make the best of their worktime, and having social interactions between employees to create a good work relationships.

Keywords: Job Related Stress, Workers, Power Plant
\end{abstract}

Korespondensi:Annisa Tria Widiaty

Email: annisatriawidiaty@upnv.ac.id 


\section{PENDAHULUAN}

Stres kerja menjadi hal umum yang dapat dialami oleh pekerja di tempat kerja, terutama pada pekerja di kota besar. Stres kerja ini diakibatkan karena ketidakmampuan seseorang dalam memenuhi tuntutan untuk menyelesaikan suatu pekerjaan yang tidak sesuai dengan kapasitas atau keterampilannya, serta adanya rasa ketidakpuasan dalam lingkungan kerja. Adanya tuntutan tertentu yang berubah dari waktu ke waktu dapat membuat pekerja merasa tertekan. Apabila perubahan ini tidak dapat disesuaikan oleh pekerja, maka hal ini dapat menjadi ancaman pekerja untuk merasa tertekan dalam bekerja sehingga dapat menimbulkan stres kerja. ${ }^{1}$

Stres adalah suatu kondisi dimana seseorang memberikan respon yang berlebih terhadap suatu tuntutan dan kemampuan yang tidak sesuai dengan yang dimilikinya. ${ }^{2}$ Stres kerja merupakan ketidaksesuaian pengetahuan dan kemampuan pekerja dalam menghadapi tuntutan atau tekanan kerja. ${ }^{3}$ Terlalu besarnya stres dapat memberikan suatu ancaman terhadap kemampuan seseorang dalam menghadapi lingkungannya.

Survey yang dilakukan pada tahun 2000 oleh European Foundation for the Improvement of Working Condition, menyatakan bahwa sekitar $28 \%$ stres kronis merupakan salah satu contoh gangguan kesehatan pada pekerja. Stres akibat kerja di Eropa menjadi masalah kesehatan kedua yang berhubungan dengan pekerjaan. ${ }^{4}$ Lalu survey yang dilakukan oleh Northwestern National Life pada pekerja Amerika menunjukkan bahwa $40 \%$ pekerjanya mengalami stres kerja dan seperempat pekerja di Amerika menganggap bahwa pekerjaan tersebut menjadi salah satu stressor utama di kehidupan mereka. $^{5}$

Badan Pusat Statistik (BPS) tahun 2014 menyatakan bahwa di Indonesia sekitar $11,6-17,4 \%$ dari 150 juta populasi orang dewasa mengalami gangguan mental emosional atau kesehatan jiwa yaitu stres kerja. ${ }^{6}$ Di Indonesia belum ada data terbaru mengenai angka stres kerja pada pekerja, namun terdapat beberapa penelitian terkait stres kerja seperti hasil penelitian pada pegawai Kementerian Kesehatan diketahui bahwa stres yang dialami oleh pegawai adalah sebesar $79 \% .^{7}$ Hasil penelitian lain yang dilakukan pada pekerja bagian produksi pada perusahaan di bidang konveksi didapatkan bahwa stres kerja yang dialami oleh pekerja sebesar $86,2 \%{ }^{8}$

Semakin tinggi persaingan dan tuntutan untuk profesional dalam dunia kerja akan mempengaruhi banyaknya tekanan yang harus dihadapi seseorang di lingkungan kerjanya. Tingkat kesehatan yang menurun dapat disebabkan karena stres yang tidak diatasi dan akan mempengaruhi kualitas dan kinerja dari pekerja. Dampak dari stres yang berhubungan dengan pekerjaan dapat menyebabkan perubahan emosional, kebiasaan atau mental, dan fisiologis. ${ }^{9}$ Stres dapat menimbulkan beberapa perubahan seperti perubahan perilaku yang dapat mempengaruhi kesehatan mental maupun fisik. Timbulnya gejala akibat stres kerja yakni gejala fisik seperti bahu menegang dan sakit kepala, gejala psikologis seperti konsentrasi yang berkurang, serta gejala perilaku seperti mudah marah dan tersinggung. ${ }^{10}$

Hurrel et al dan Cooper dalam Munandar menyebutkan bahwa terdapat beberapa faktor yang bertindak sebagai sumber potensial dari stres kerja yaitu beban kerja, upah kerja, kebisingan, peran individu dalam organisasi, pengembangan karir, hubungan dalam pekerjaan, usia, jenis kelamin, masa kerja, status perkawinan, dan tingkat Pendidikan. ${ }^{11}$ Stres kerja yang tidak dikendalikan dengan segera dapat menimbulkan dampak terhadap kesehatan individu seperti adanya perubahan-perubahan pada kondisi fisik maupun mental.

Berdasarkan studi pendahuluan di Proyek PLTGU Muara Tawar PT Hutama Karya, terdapat 4 dari 7 karyawan mengalami bosan, jenuh, suka menunda pekerjaan, menurunnya semangat dalam bekerja dimana hal tersebut merupakan gejala stres kerja yang dapat terjadi. Stres kerja perlu dikelola agar kesehatan pekerja tidak terganggu sehingga tidak akan menurunkan kualitas pekerjaannya dan mempengaruhi tingkat kinerjanya dimana 
hal tersebut juga akan berdampak pada perusahaan.

Proyek PLTGU Muara Tawar merupakan proyek yang terbilang cukup padat dengan segala aktivitas pekerjaan yang ada dengan adanya suatu target yang telah ditetapkan oleh perusahaan. Tugas atau tuntutan kerja yang ada dapat menimbulkan suatu perasaan tertekan yang dialami karyawan sehingga dapat menyebabkan stres kerja. Perasaan jenuh dan bosan yang dirasakan karyawan adalah salah satu tanda dari stres kerja. Selain itu, kurangnya dukungan seperti kurangnya apresiasi terhadap kinerja yang telah diberikan karyawan dan komunikasi yang kurang baik antar rekan kerja atau atasan mempengaruhi menurunnya semangat dalam melakukan pekerjaan sehingga dengan tugas yang ada dengan kurangnya motivasi untuk menyelesaikan pekerjaan dapat menyebabkan karyawan mengalami stres kerja.

Berdasarkan hal tersebut, peneliti melakukan penelitian mengenai stres kerja pada karyawan di proyek PLTGU Muara Tawar PT Hutama Karya.

\section{METODE}

Penelitian ini bersifat analitik kuantitatif dengan desain studi Cross-Sectional. Populasi dalam penelitian ini yaitu seluruh karyawan Proyek PLTGU Muara Tawar PT Hutama Karya Kabupaten Bekasi. Teknik pengambilan sampel yang digunakan yaitu secara acak atau simple random sampling. Besar sampel ditentukan dengan rumus slovin didapatkan sebanyak 107 responden lalu dilakukan penambahan $10 \%$ sehingga diperoleh sampel sebanyak 118 responden. Pengumpulan data dilakukan menggunakan kuesioner yang disebarkan kepada responden. Kriteria inklusi pada penelitian ini yaitu responden merupakan pekerja di Proyek PLTGU Muara Tawar PT Hutama Karya. Sedangkan eksklusinya yaitu responden yang sedang sakit atau tidak hadir pada saat dilakukannya pengambilan data.

Data yang dikumpulkan merupakan data primer yang diperoleh dari kuesioner serta data sekunder didapatkan dari perusahaan yang berisikan gambaran umum perusahaan, data jumlah pekerja dan daftar nama pekerja. Variabel independen dalam penelitian ini adalah usia, masa kerja, tingkat pendidikan, beban kerja mental, dan hubungan dalam pekerjaan. Sedangkan variabel dependen adalah stres kerja.

Pada kuesioner stres kerja menggunakan kuesioner The Workplace Stress Scale oleh The Marlin Company and The American Institute of Stress. Pengategorian stres kerja dilihat dari skor baku yang telah ditetapkan lalu dibandingkan dengan hasil penilaian kuesioner sehingga didapatkan tiga kategori yaitu tidak ada stres, stres ringan, dan stres sedang. Pada pengukuran beban kerja mental menggunakan kuesioner dengan metode NASA-TLX yang terdiri dari 6 indikator beban kerja mental, dimana terdapat dua tahap pengukuran. Tahap pertama yaitu pembobotan dan tahan pemberian rating pada tiap indikator. Setelah didapatkan skor pada pembobotan dan rating lalu nilai tersebut dikalikan kemudian dijumlah dan dibagi 15 sehingga didapatkan skor akhir dan dikategorikan menjadi beban kerja ringan, sedang, dan berat. Lalu pada kuesioner hubungan dalam pekerjaan diambil dari penelitian terdahulu ${ }^{12}$ dimana terdapat 6 pertanyaan yang berisikan pertanyaan mengenai hubungan antara atasan dan rekan kerja dan hasil akhirnya berupa skor dengan kategori baik jika skor $>23$ atau buruk jika skor $\leq 23$.

Analisis yang dilakukan pada penelitian ini yaitu analisis univariat. Analisis univariat dilakukan untuk mendapatkan distribusi frekuensi dari setiap variabel yang diteliti. Etika dalam penelitian ini yaitu responden berhak untuk memilih ikut berpatisipasi dalam penelitian atau tidak dan peneliti menjamin keamanan serta kerahasiaan responden. Penelitian ini telah disetujui oleh Komisi Etik Penelitian Kesehatan Universitas Pembangunan Nasional Veteran Jakarta dengan Nomor : 24/I/2021/KEPK.

\section{HASIL}

Berdasarkan hasil analisis univariat, diketahui bahwa mayoritas karyawan 
mengalami stres kerja yang berada pada kategori ringan sebanyak 89 karyawan $(75,4 \%)$ dan 24 karyawan (20,3\%) tidak mengalami stres kerja. Tidak terdapat perbedaan signifikan antara karyawan yang berusia muda $(\leq 32$ tahun) dan karyawan yang berusia tua $(>32$ tahun) dengan rata-rata usia karyawan adalah 35 tahun, usia termuda yaitu 18 tahun dan usia tertua yaitu 62 tahun. Pengategorian usia ini didapatkan dengan menggunakan nilai Median dikarenakan variabel usia tidak terdistribusi normal.

Masa kerja karyawan tidak memiliki perbedaan signifikan antara masa kerja baru $(\leq$ 21 bulan) dan masa kerja lama ( $>21$ bulan) dengan rata-rata masa kerja karyawan adalah 21 bulan, masa kerja terbaru yaitu 2 bulan dan masa kerja terlama yaitu 45 bulan. Tingkat pendidikan karyawan paling banyak pada pendidikan tinggi, yaitu tamat SMA sebanyak 54 karyawan $(45,8 \%)$ dan perguruan tinggi sebanyak 52 karyawan $(44,1 \%)$.

Pada faktor intrinsik pekerjaan yaitu variabel beban kerja mental didapatkan mayoritas karyawan memiliki beban kerja mental dalam kategori sedang sebanyak 69 karyawan $(58,5 \%)$ dan tidak ada karyawan yang memiliki beban kerja mental dalam kategori ringan. Dari hasil tersebut dapat diketahui bahwa karyawan merasa jika pekerjaan yang dimiliki terlalu banyak dengan tenggat waktu yang tidak wajar.

Pada faktor ekstrinsik pekerjaan yaitu pada variabel hubungan dalam pekerjaan didapatkan sebagian besar karyawan memiliki hubungan baik dalam pekerjaan sebanyak 66 karyawan (92,3\%) dan karyawan yang memiliki hubungan buruk dalam pekerjaan sebanyak 52 karyawan $(44,1 \%)$.

Hasil penelitian menunjukkan bahwa banyaknya karyawan yang mengeluhkan sedikitnya atau bahkan tidak adanya penghargaan yang sesuai terhadap kinerja yang dilakukan. Lalu karyawan merasa sulit untuk mengeskpresikan pendapat atau perasaannya mengenai kondisi pekerjaan kepada atasan serta merasa jika pendapat atau ide mereka kurang diterima dengan baik sehingga mempengaruhi semangat atau motivasi ketika bekerja (Tabel 1)

\section{Tabel 1. Distribusi Variabel Dependen dan Independen}

\begin{tabular}{|c|c|c|}
\hline Variabel & $\begin{array}{c}\text { Jumlah } \\
\text { (n) }\end{array}$ & $\begin{array}{c}\text { Presentase } \\
\text { (\%) }\end{array}$ \\
\hline \multicolumn{3}{|l|}{ Stres Kerja } \\
\hline Tidak Stres & 24 & 20,3 \\
\hline Stres Ringan & 89 & 75,4 \\
\hline Stres Sedang & 5 & 4,2 \\
\hline \multicolumn{3}{|l|}{ Usia } \\
\hline Muda ( $\leq 32$ tahun) & 60 & 50,8 \\
\hline Tua ( $>32$ tahun) & 58 & 49,2 \\
\hline \multicolumn{3}{|l|}{ Masa Kerja } \\
\hline Baru $(\leq 21$ bulan $)$ & 60 & 50,8 \\
\hline Lama (>21 bulan) & 58 & 49,2 \\
\hline \multicolumn{3}{|l|}{ Tingkat Pendidikan } \\
\hline $\mathrm{SD}$ & 1 & 0,8 \\
\hline SMP & 11 & 9,3 \\
\hline SMA & 54 & 45,8 \\
\hline Perguruan Tinggi & 52 & 44,1 \\
\hline \multicolumn{3}{|l|}{ Beban Kerja Mental } \\
\hline Sedang & 69 & 58,5 \\
\hline Berat & 49 & 41,5 \\
\hline \multicolumn{3}{|c|}{ Hubungan dalam Pekerjaan } \\
\hline Baik & 66 & 55,9 \\
\hline Buruk & 52 & 44,1 \\
\hline
\end{tabular}

\section{PEMBAHASAN}

Responden dalam penelitian ini sebagian besar mengalami stres kerja dalam kategori ringan. Hal ini dapat disebabkan karena masih adanya kemampuan karyawan untuk menyelesaikan suatu pekerjaannya serta adanya ketahanan dalam dirinya untuk menghadapi stres kerja yang mungkin dialaminya. Stres yang mungkin dialami karyawan dapat diatasi dengan menerapkan manajemen stres sedini mungkin serta memanfaatkan waktu istirahat dengan baik untuk mengurangi ketegangan yang ada pada tubuh. Karyawan di Proyek PLTGU Muara Tawar memiliki proporsi usia muda dan usia tua serta proporsi masa kerja baru dan masa kerja lama yang tidak jauh berbeda dikarenakan banyaknya karyawan yang baru bekerja pada proyek dengan 
mayoritas karyawan berpendidikan SMA dan perguruan tinggi.

Sebagian besar karyawan di Proyek PLTGU Muara Tawar memiliki beban kerja mental dalam kategori sedang. Hal ini berarti tuntutan kerja yang dirasakan tidak melebihi kapasitas maksimum yang dimiliki karyawan serta mayoritas karyawan masih mampu untuk menyelesaikan pekerjaannya dari waktu ke waktu. Kurang baiknya hubungan yang terjalin antar pekerja dapat mempengaruhi kehidupan sosial dalam bekerja dimana buruknya komunikasi atau kurangnya dukungan dapat menyebabkan perasaan kurang dihargai.

Sebuah penelitian mengemukakan bahwa perasaan tertekan ketika bekerja akibat adanya tuntutan atau tekanan kerja yang tidak sesuai dengan pengetahuan dan kemampuan yang dimiliki oleh pekerja dapat menimbulkan stres di tempat kerja. Selain itu stres kerja juga dapat terjadi jika pekerja tidak dapat beradaptasi dengan perubahan lingkungan kerja atau tekanan yang ada. ${ }^{13}$

Penelitian yang dilakukan terhadap karyawan E-Centric Solutions menyatakan bahwa karyawan mengalami stres pada kategori sedang. ${ }^{14}$ Lalu penelitian yang dilakukan terhadap karyawan non manajerial pada PT AstraZeneca Indonesia dengan hasil tingkat stres kerja yang dialami karyawan berada pada kategori sedang ${ }^{15}$. Selain itu hasil penelitian terhadap karyawan pada PT Pikiran Rakyat menunjukkan bahwa karyawan memiliki tingkat stres kerja dalam kategori sedang. ${ }^{16}$

Ketika karyawan menghabiskan banyak waktu dan energinya dalam pekerjaannya serta mendapat tugas yang sulit tetapi upah, promosi jabatan, kualitas hubungan interpersonal yang didapatkan tidak sesuai daripada yang diharapkan maka akan mudah untuk menyebabkan stres kerja. ${ }^{17}$ Beberapa karyawan di Proyek PLTGU Muara Tawar mengalami gejala dari stres kerja seperti merasa bosan, jenuh, suka menunda pekerjaan, dan menurunnya semangat dalam bekerja.

Setelah dilakukan analisis didapatkan hasil bahwa karyawan dalam penelitian ini sebagian besar mengalami stres kerja ringan.
Hal ini dapat disebabkan karena masih adanya kemampuan karyawan untuk menyelesaikan suatu pekerjaannya serta adanya ketahanan dalam dirinya untuk menghadapi stres kerja yang mungkin dialaminya. Berdasarkan hasil pada kuesioner didapatkan beberapa karyawan menghadapi kondisi kerja yang tidak menyenangkan atau tidak aman. Kondisi kerja tersebut apabila dirasakan dalam waktu lama dapat menyebabkan perubahan-perubahan fisik ataupun emosi pada karyawan. Selain itu karyawan merasa bahwa pekerjaan yang dimiliki terlalu banyak atau tenggat waktu yang tidak wajar. Karyawan menganggap untuk menyelesaikan pekerjaan yang banyak dalam waktu singkat sebagai aspek negatif. Dengan adanya target seperti itu dapat menciptakan semangat kerja yang rendah dan ketidakpuasan kerja. ${ }^{14}$ Stres yang mungkin dialami karyawan dapat diatasi dengan menerapkan manajemen stres sedini mungkin, mengatur waktu sebaik mungkin serta memanfaatkan waktu istirahat dengan baik untuk mengurangi ketegangan yang ada pada tubuh.

Karyawan di Proyek PLTGU Muara Tawar memiliki perbedaan proporsi usia dan masa kerja yang tidak signifikan dikarenakan karyawan yang bekerja di proyek tersebut bersifat tidak tetap sehingga adanya pergantian karyawan serta mayoritas karyawan berpendidikan SMA dan perguruan tinggi. Sebagian besar karyawan di Proyek PLTGU Muara Tawar memiliki beban kerja mental sedang. Hal ini berarti tuntutan kerja yang dirasakan tidak melebihi kapasitas maksimum yang dimiliki karyawan serta mayoritas karyawan masih mampu untuk menyelesaikan pekerjaannya dari waktu ke waktu. Akan tetapi hal ini dapat menimbulkan kelelahan baik psikis maupun fisik pada karyawan sehingga akan menjadi sebuah tekanan kerja yang biasanya datang pada pertengahan dan akhir tahun dimana mereka harus bisa hampir mencapai target.

Kurang baiknya hubungan yang terjalin antar pekerja dapat memengaruhi kehidupan sosial dalam bekerja dimana buruknya komunikasi atau kurangnya dukungan dapat menyebabkan perasaan kurang dihargai. 
Diperoleh hasil bahwa banyaknya karyawan di Proyek PLTGU Muara Tawar yang mengeluhkan sedikitnya atau bahkan tidak adanya penghargaan yang sesuai terhadap kinerja yang dilakukan. Lalu karyawan merasa sulit untuk mengeskpresikan pendapat atau perasaannya mengenai kondisi pekerjaan kepada atasan serta merasa jika pendapat atau ide mereka kurang diterima dengan baik sehingga mempengaruhi semangat atau motivasi ketika bekerja. Oleh karena itu, perlunya membina komunikasi yang lebih baik antara atasan dengan karyawan, karyawan dengan karyawan lain agar tujuan perusahaan dapat tercapai dan karyawan merasa nyaman dalam melakukan pekerjaannya.

\section{KESIMPULAN}

Sebagian besar karyawan di Proyek PLTGU Muara Tawar PT Hutama Karya mengalami stres kerja ringan, Pada karakteristik individu, tidak ada perbedaan yang signifikan antara usia muda dan usia tua, masa kerja baru dan masa kerja lama, serta mayoritas karyawan memiliki tingkat pendidikan tinggi yaitu SMA dan perguruan tinggi. Pada faktor intrinsik pekerjaan, mayoritas karyawan memiliki beban kerja mental sedang. Dan pada faktor ekstrinsik pekerjaan, mayoritas karyawan memiliki hubungan yang baik dalam pekerjaan baik antara rekan kerja maupun atasan.

Peneliti menyarankan agar perusahaan membuat suatu program terkait adanya peregangan atau stretching bersama pada jam tertentu untuk mengurangi kejenuhan pekerja terhadap rutinitas kerja yang monoton, mengadakan pelatihan atau training pada pekerja baru agar dapat beradaptasi dengan tugasnya dan situasi di tempat kerja., mengadakan suatu kegiatan seperti family gathering untuk membina hubungan antar pekerja yang baik serta memberikan apresiasi atau reward pada pekerja dengan kinerja terbaik.

\section{DAFTAR PUSTAKA}

1. Fahmi S. Pengaruh Stres Kerja Dan Konflik Kerja Terhadap Semangat Kerja
Karyawan Pada PT. Omega Mas Pasuruan. J Ekon Mod. 12(3), 107-116, https://doi.org/10.21067/jem.v12i3.1462

2. Ibrahim H, Amansyah M, Yahya GN. Faktor - Faktor yang Berhubungan dengan Stres Kerja pada Pekerja Factory 2 PT . Maruki Internasional Indonesia Makassar. Al-Sihah Public Heal Sci J [Internet]. 2016;8(1):60-8. Available from: http://journal.uinalauddin.ac.id/index.php/Al-

Sihah/article/view/2082. Diakses pada 28 Januari 2021.

3. Leka S, Griffith A, Cox T. Work Organization and Stress: Systematic Problem Approaches for Employee, Managers, and Trade Union Representatives [Internet]. Protecting. Switzerland: WHO; 2003. Available from: https://apps.who.int/iris/bitstream/handle/1 0665/42625/9241590475.pdf?sequence $=1$ \&isAllowed=y. Diakses pada 17 Januari 2021.

4. European Foundation. Third European survey on working conditions 2000 [Internet]. Luxembourg: Office for Official Publications of the European Communities; 2001. Available from: https://www.eurofound.europa.eu/sites/def ault/files/ef_publication/field_ef_documen t/ef0121en.pdf. Diakses pada 25 Mei 2021.

5. National Institute for Occupational Safety and Health. Stress at Work [Internet]. Columbia Parkway; 1999. Available from: https://www.cdc.gov/niosh/docs/99101/pdfs/99101.pdf?id=10.26616/NIOSHPUB99101. Diakses pada 25 Mei 2021.

6. Setiawan MR. Analisis Faktor Resiko Stress Akibat Kerja pada Pekerja Sektor Formal dan Sektor Informal di Kota Semarang Analysis of Stress Risk Factors Due to Work in Formal Sector Workers and Informal Sector in Semarang City. 2019;1(1). https://doi.org/10.26714/medart.1.1.2019. 29-36

7. Besral, Widiantini W. Determinan Stres pada Pegawai Kementerian Kesehatan. J 
Kesehat Masy Nas. 2015;9(3). http://dx.doi.org/10.21109/kesmas.v9i3.56 8

8. Setiawan DA, Sofiana L. Faktor-Faktor yang Berhubungan Dengan Stres Kerja di PT. Chanindo Pratama Piyungan Yogyakarta. J Kesehat Masy [Internet]. 2013;6(5). Available from: http://hdl.handle.net/11617/5251. Diakses pada 11 Januari 2021.

9. Tarwaka. Ergonomi Industri Dasar Dasar Pengetahuan Ergonomi dan Aplikasi di Tempat Kerja. Surakarta: Harapan Press; 2015.

10. Salafi N. Faktor-faktor yang Berhubungan dengan Stres Kerja Pada Pekerja Bagian Operasional PT. Gunze Indonesia. [Internet]. Universitas Indonesia; 2008. Available from: http://lib.ui.ac.id/file?file=digital/122799-

S-5368-Faktor-faktor-HA.pdf. Diakses pada 17 Januari 2021.

11. Munandar AS. Psikologi Industri dan Organisasi. Jakarta: Universitas Indonesia (UI-Press); 2014.

12. Solichatunnisa AW. Faktor-Faktor Yang Berhubungan Dengan Stres Kerja Pada Polisi Lalu Lintas di POLRESTA Depok Tahun 2017 [Internet]. 2017. Available from:

http://repository.upnvj.ac.id/1575/1/AWA L.pdf. Diakses pada 11 Januari 2021.

13. Suryani NK, Yoga GADM. Konflik dan Stres Kerja dalam Organisasi. J Widya Manaj [Internet]. 2018;1(1). Available from:

https://media.neliti.com/media/publication s/298813-konflik-dan-stres-kerja-dalam- organisasi-d5830cc3.pdf. Diakses pada 25 Mei 2021.

14. Bhoganadam SD, Rao DS, Reddy AM. A Study on Job Stress among Employees at Entrepreenur's Organization: A Case Study of E-Centric Solutions Private Limited. Asian J Res Soc Sci Humanit [Internet]. 2015;5(12):103. Available from: https://www.researchgate.net/publication/ 285991512_A_Study_on_Job_Stress_amo ng_Employees_at_Entrepreenur's_Organi zation_A_Case_Study_of_E-

Centric_Solutions_Private_Limited. Diakses pada 117 Januari 2021.

15. Andriani F. Analisis Tingkat Stress Kerja Karyawan Non Manajerial Pada PT AstraZeneca Indonesia [Internet]. UI Library. Universitas Indonesia; 2012. Available from: http://lib.ui.ac.id/detail?id=20318873\&lok asi=lokal. Diakses pada 19 Januari 2021.

16. Gilang A, Wanara B, Pangarso A. Analisis Stres Kerja Karyawan Pada PT. Pikiran Rakyat. J Manaj Indones [Internet]. 2017;15(3):195. Available from: https://www.researchgate.net/publication/ 321304971_ANALISIS_STRES_KERJA KARYAWĀN PADA PTPIKIRAN RA KYAT. Diakses pada $1 \overline{7}$ Januari $202 \overline{1}$.

17. Li Y, Sun X, Ge H, Liu J, Chen L. The status of occupational stress and its influence the quality of life of coppernickel miners in Xinjiang, China. Int $\mathrm{J}$ Environ Res Public Health [Internet]. 2019;16(3). Available from: https://pubmed.ncbi.nlm.nih.gov/3069118 6/. Diakses pada 17 Januari 2021. 